\title{
Investigations for machinability of primary recycled thermoplastics with secondary recycled rapid tooling
}

\author{
PIYUSH BEDI ${ }^{1,2}$, RUPINDER SINGH $^{1, *}$ and I P S AHUJA ${ }^{2}$ \\ ${ }^{1}$ Department of Production Engineering, Guru Nanak Dev Engineering College, Ludhiana, India \\ ${ }^{2}$ Department of Mechanical Engineering, Punjabi University, Patiala, India \\ e-mail: piyush.bedi1@gmail.com; rupindersingh78@yahoo.com; ahujaips@gmail.com
}

MS received 12 April 2019; revised 3 July 2019; accepted 29 July 2019

\begin{abstract}
This paper highlights the machinability of primary recycled thermoplastics as workpiece (WP) material with secondary recycled (reinforced) thermoplastic composites as rapid tooling (RT). Both WP and RT have been 3D printed on commercial fused deposition modelling. For investigating machinability of primary recycled thermoplastics, un-reinforced WP of low-density polyethylene (LDPE) and high-density polyethylene (HDPE) has been selected. The RT materials were secondary reinforced (recycled) LDPE with double particle size $\mathrm{Al}_{2} \mathrm{O}_{3}$ particles and HDPE with triple particle size $\mathrm{Al}_{2} \mathrm{O}_{3}$. The machinability has been calculated in terms of weight loss of WP, while machining on a vertical milling set-up. This study also reports the surface hardness, porosity, surface roughness (Ra) and photomicrographic observations of WP and RT under controlled machining conditions. Further thermal analysis suggests that primary recycled thermoplastic can be successfully machined with secondary recycled RT, resulting in improved thermal stability and surface properties.
\end{abstract}

Keywords. Machinability; $\mathrm{Al}_{2} \mathrm{O}_{3}$; fused deposition modelling; LDPE; HDPE; surface properties.

\section{Introduction}

The pollution caused due to plastic disposal has been identified as one of the major threat to the environment [1-3]. To avoid this, plastic recycling and processing has increased extensively in modern times [2-5]. In the recent past, some studies have been reported for primary, secondary, tertiary and quaternary means of recycling in the field of plastic solid waste (PSW) management with metallic/non-metallic reinforcements via rapid prototyping (RP) route [5-9]. Recycling has proven to be one of the best possible ways to manage the polymer waste $[10,11]$. Previous studies have shown that the recycling of PSW can be performed number of times for enhancing the reusability of waste polymers. Some studies outlined the enhancement in mechanical and metallurgical properties with use of metallic powder reinforcements in polymer wastes [5-7]. It has been reported that thermoplastics are versatile materials from their commercial use point of view and also have sustainability features [8]. Literature review outlined that the cost of replacing thermoplastics with alternative materials would be 4 times higher. For example the use of thermoplastics in commercial vehicles will help reduce 30001 of fuel in total life span [9], improve failure rate for plastic pipes $(\geq 100$ years) [10] and requires $\leq 4 \%$ of water to make poly-bags in comparison with paper-bags [11]. The

*For correspondence

Published online: 11 September 2019 thermoplastics have high ability to be moulded into finished form without any post-processing requirements [12]. Typical shapes, holes and undercuts can be easily moulded with reduced tooling cost using RP-assisted rapid tooling (RT). From commercial application viewpoint, when a plastics component is specified and the number to be used is small, then machining the component is more economical. It should be noted that not all thermoplastics materials can be machined [13]. As a thumb rule, if a thermoplastic is more rigid then it becomes easier to be machined. Some commercial manufacturers have reported use of machinability index as a nominal ranking out of 20 (best value) while machining with conventional set-up/ CNC [14]. It has been observed that due to poor thermal conductivity and low melting point of thermoplastics, heat generation must be kept to a minimum. The value of machinability index for thermoplastics is available only for virgin and commercial grades of thermoplastics, whereas for recycled (primary/secondary), no such index is available. Recent studies showed that RT can be developed using waste/recycled polymers and metallic reinforcements [15-20].

This work is an extension of work reported on reinforced thermoplastic composites (secondary recycled) as RT [21-23] and is focussed on machinability of thermoplastics workpiece (WP) material (primary recycled). It should be noted that the machinability index for thermoplastics is available only for commercial grade of virgin 


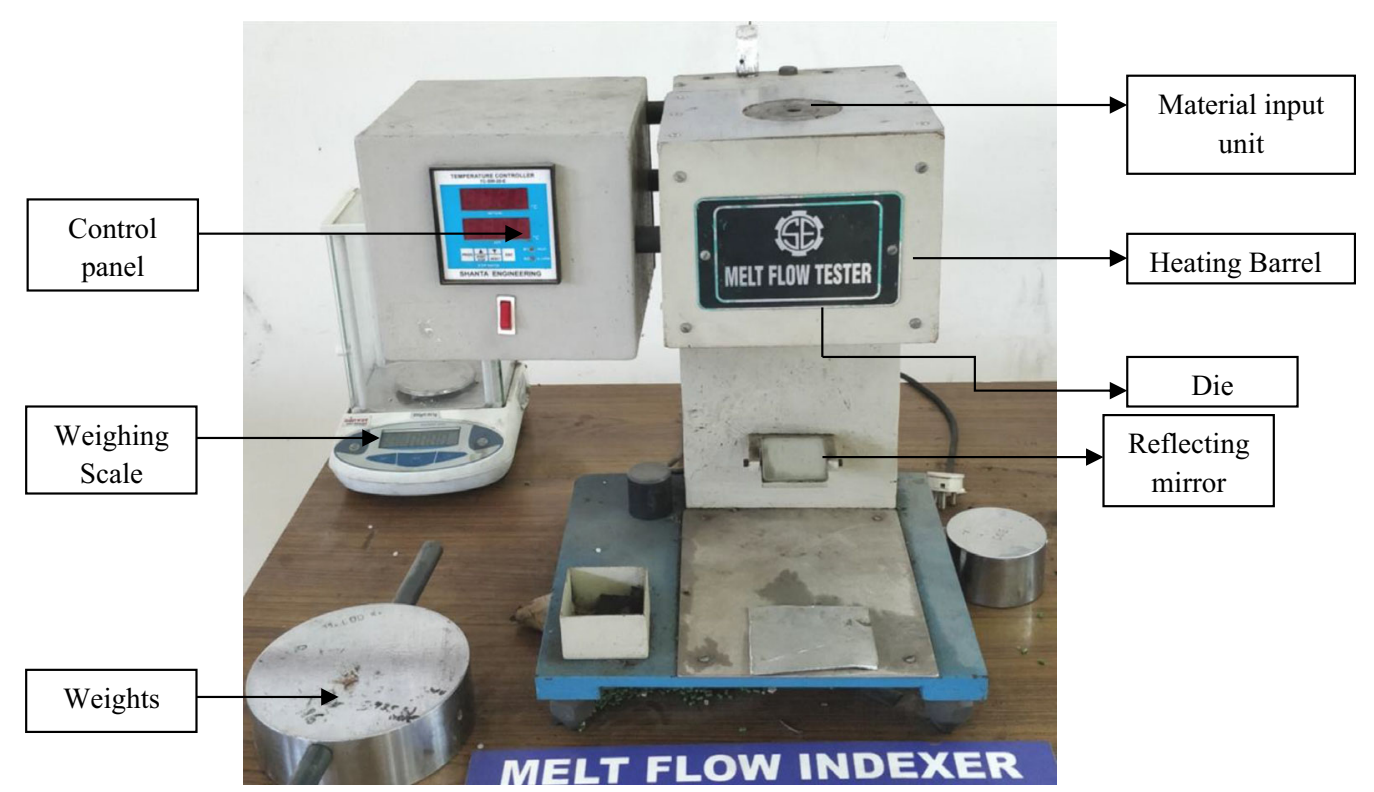

Figure 1. MFI tester used in study.

Table 1. Fixed input parameters for printing of WP and RT.

\section{Static parameters for FDM}

Nozzle diameter $(\Phi 0.3 \mathrm{~mm})$

Wire diameter $(\Phi 1.75 \pm 0.05 \mathrm{~mm})$

Bed temperature $\left(55 \pm 2{ }^{\circ} \mathrm{C}\right)$

Printing temperature $\left(155 \pm 5^{\circ} \mathrm{C}\right.$ for LDPE and $170 \pm 5^{\circ} \mathrm{C}$ for HDPE)
Infill density $(80 \%)$

Infill angle $\left(60^{\circ}\right)$

Infill speed $(60 \mathrm{~mm} / \mathrm{s})$

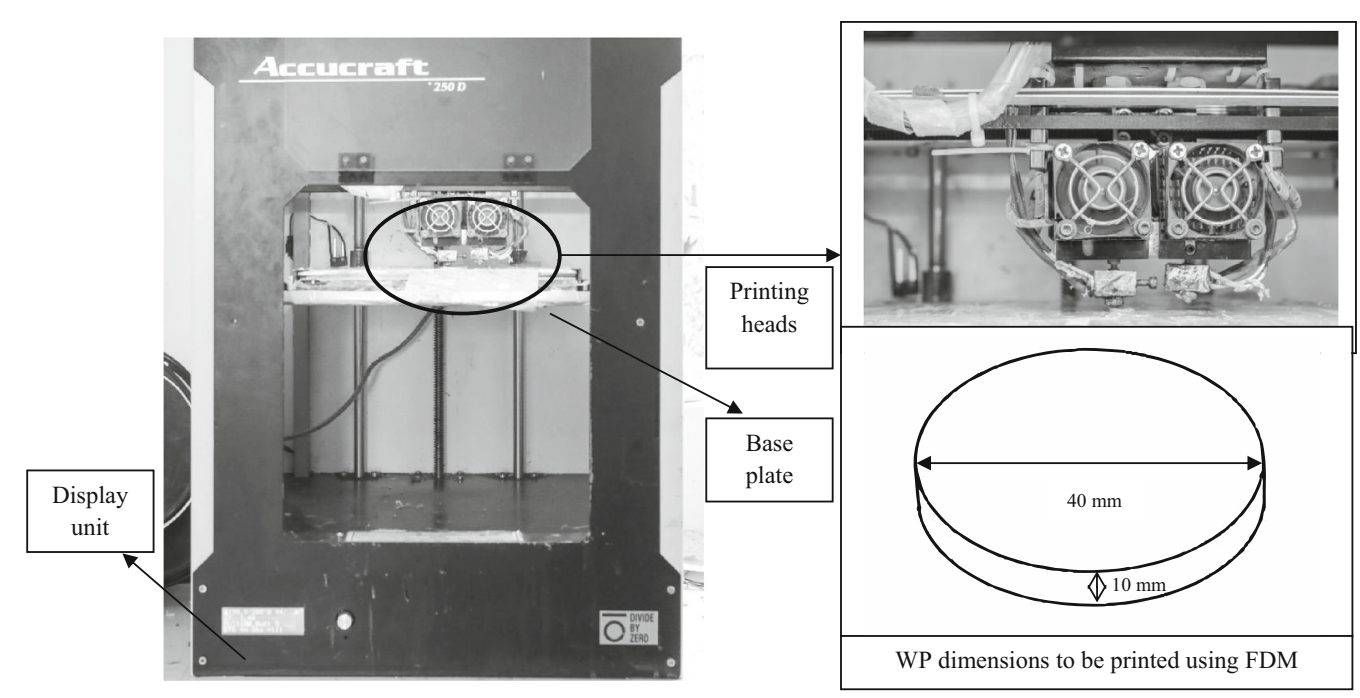

Figure 2. FDM set-up (Make: Divide by Zero, India).

thermoplastics. However, hitherto very little has been reported on machinability of primary and secondary recycled thermoplastics. In this study both WP and RT have been $3 \mathrm{D}$ printed with commercial open source fused deposition modelling (FDM). The WP material has been selected as primary recycled low-density polyethylene (LDPE) and high-density polyethylene (HDPE), whereas RT materials were secondary, reinforced LDPE with double 

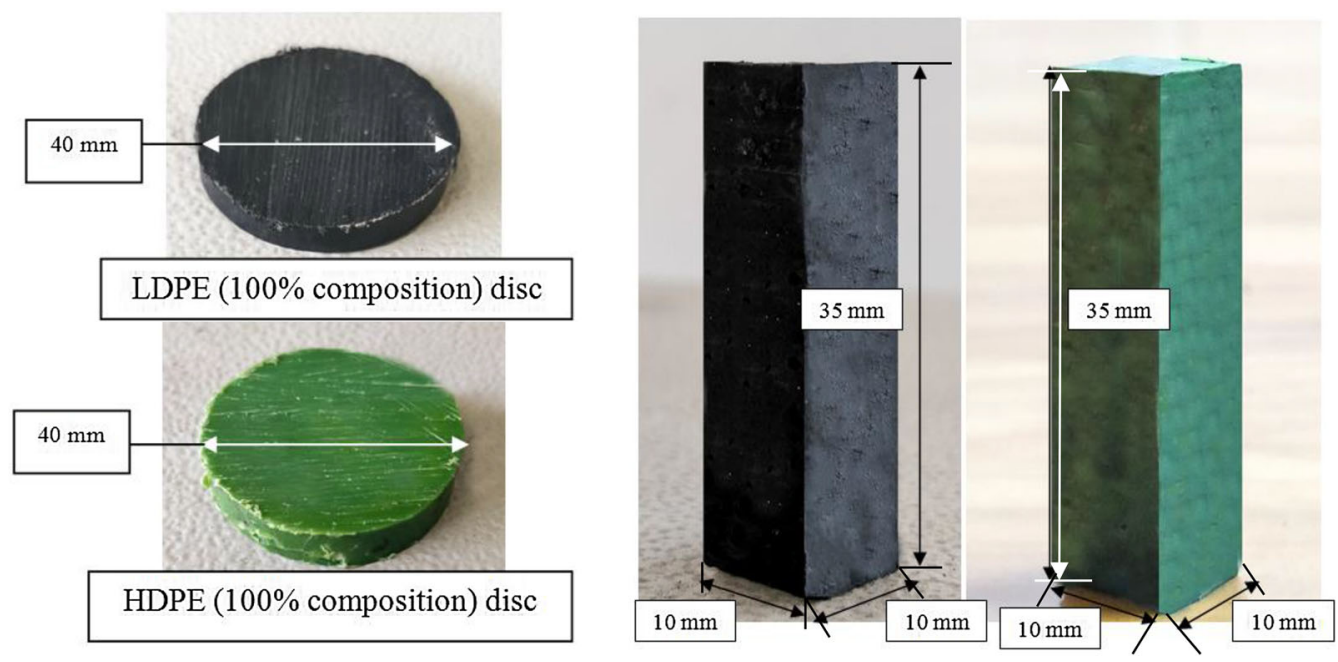

Figure 3. 3D view of WP and RT prepared.

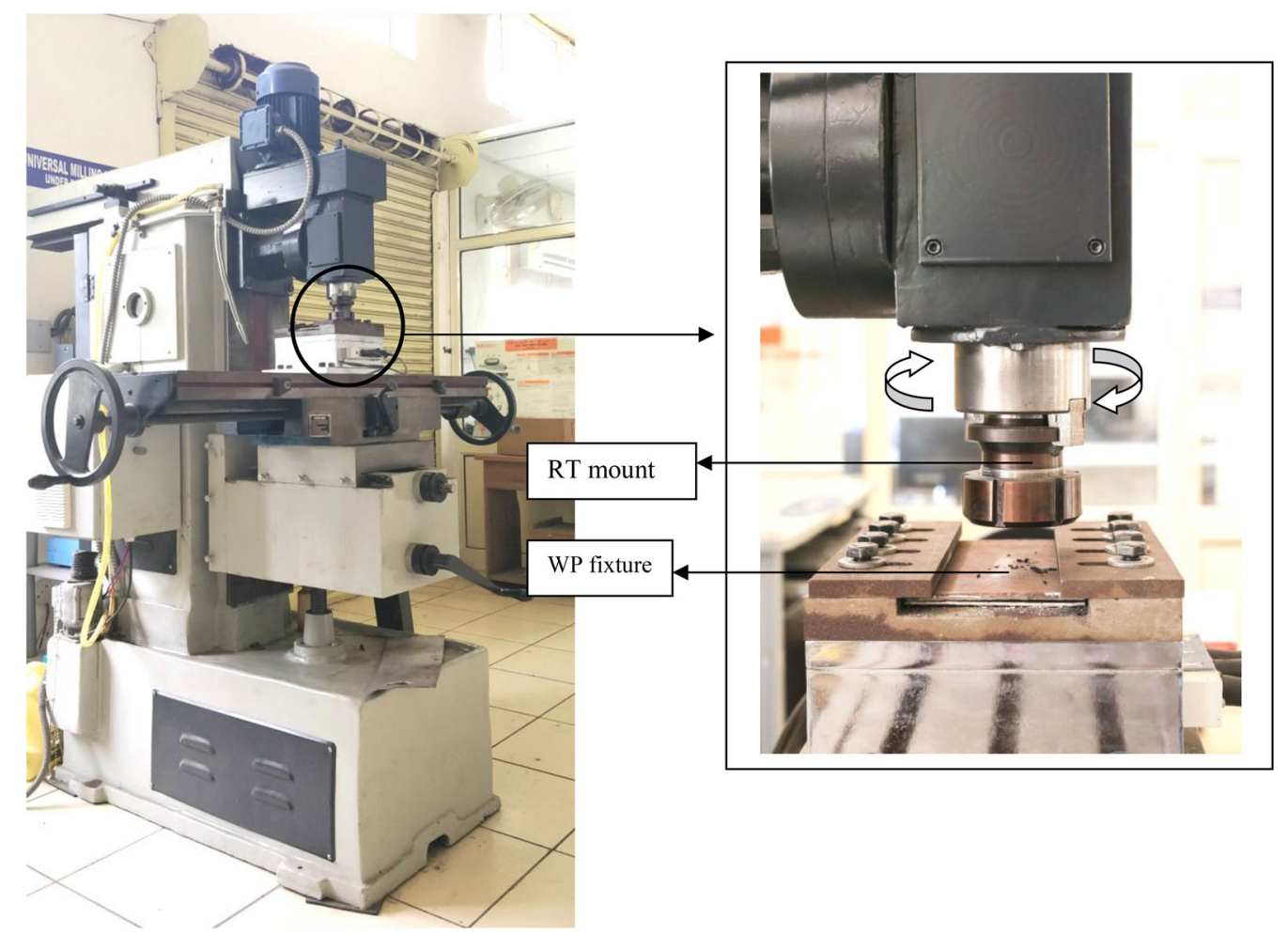

Figure 4. Vertical milling machine set-up.

particle size (DPS) $\mathrm{Al}_{2} \mathrm{O}_{3}$ particles and HDPE with triple particle size (TPS) $\mathrm{Al}_{2} \mathrm{O}_{3}$. It should be noted that DPS refers to particle size of 100 and $120 \mu \mathrm{m}$ (in equal weight proportion) and TPS refers to particle size of 100, 120 and $150 \mu \mathrm{m}$ (in equal weight proportion) [21-23]. Thermoplastic granules and reinforcements were blended by a twin screw extruder (TSE). The feedstock filament prepared was made to run on FDM set-up to print 3D functional prototype, i.e. WP and RT. The 3D printed WP was further mounted on a fixture for possible machining with RT on vertical milling set-up (for machinability evaluation). The changes in surface hardness, porosity, Ra and morphology (based upon photomicrographs) of WP under machining conditions have been reported. 


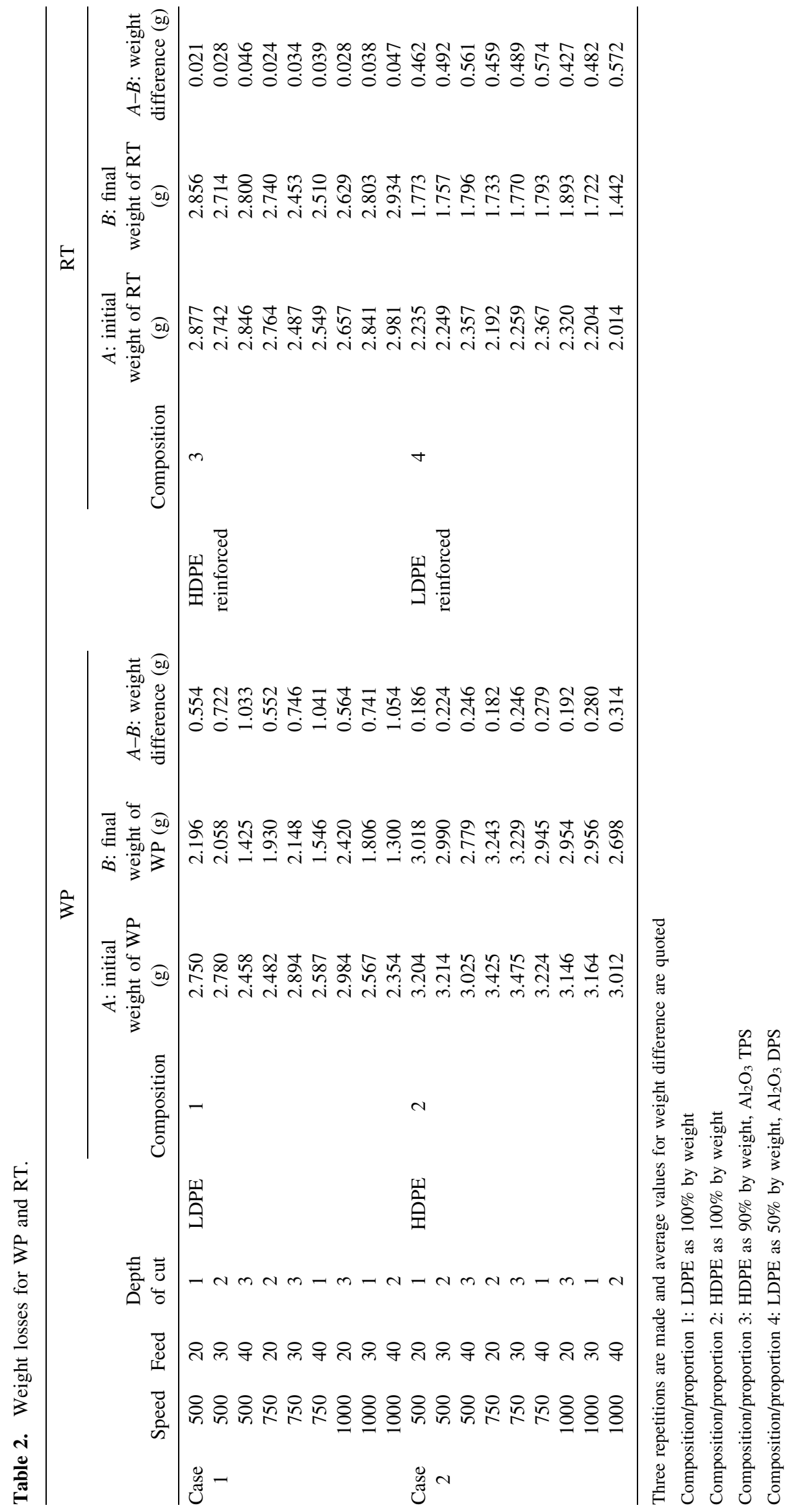


Table 3. SN ratios for weight loss of WP.

\begin{tabular}{lrrrr}
\hline Composition & Speed & Feed & $\begin{array}{c}\text { Depth of } \\
\text { cut }\end{array}$ & $\begin{array}{c}\text { SN ratios for weight } \\
\text { loss of RT }\end{array}$ \\
\hline Case 1 & & & & \\
1 & 500 & 20 & 1 & -5.12980 \\
& 500 & 30 & 2 & -2.82926 \\
& 500 & 40 & 3 & 0.28201 \\
& 750 & 20 & 2 & -5.16122 \\
& 750 & 30 & 3 & -2.54522 \\
& 750 & 40 & 1 & 0.34901 \\
& 1000 & 20 & 3 & -4.97442 \\
& 1000 & 30 & 1 & -2.60364 \\
& 1000 & 40 & 2 & 0.45681 \\
& & & & -14.6097 \\
& 500 & 20 & 1 & -12.9950 \\
& 500 & 30 & 2 & -12.1813 \\
& 500 & 40 & 3 & -14.7986 \\
& 750 & 20 & 2 & -12.1813 \\
& 750 & 30 & 3 & -11.0879 \\
& 750 & 40 & 1 & -14.3340 \\
& 1000 & 20 & 3 & -11.0568 \\
& 1000 & 30 & 1 & -10.0614 \\
\hline 1000 & 40 & 2 &
\end{tabular}

Note: Negative SN ratio shows that signal power is less than noise power. For calculation of SN ratio, larger the better type case was used as per the formula: $\eta=-10 \log \left[\frac{1}{n} \sum_{k=1}^{n} \frac{1}{y^{2}}\right]$, where $\eta$ is $\mathrm{SN}$ ratio, $n$ is the no. of experiment and $y$ is the material property at experiment no. $k$. Since for calculation logarithmic scale is used, if the value of $y$ is $<1$, negative SN ratio values are observed.

\section{Experimentation}

Based upon pilot experimentations, different proportions of LDPE and HDPE granules along with $\mathrm{Al}_{2} \mathrm{O}_{3}$ and $\mathrm{SiC}$ reinforcements were blended. The different blends were put into a melt flow tester to check melt flow indices (MFI). It was observed in pilot studies that recycled LDPE when mixed with DPS $\mathrm{Al}_{2} \mathrm{O}_{3}$ and recycled HDPE when mixed
Table 5. Percentage (\%) contribution of input parameter on weight loss of WP.

\begin{tabular}{lcc}
\hline Parameter & $\begin{array}{c}\text { Contribution on weight } \\
\text { loss of WP }(\%)(\text { Case 1) }\end{array}$ & $\begin{array}{c}\text { Contribution on weight } \\
\text { loss of WP (\%) (Case 2) }\end{array}$ \\
\hline Speed & 0.11 & 13.51 \\
Feed & 99.82 & 81.91 \\
Depth of & 0.03 & 2.69 \\
$\quad$ cut & & 1.89 \\
Error & 0.04 & \\
\hline
\end{tabular}

with TPS $\mathrm{Al}_{2} \mathrm{O}_{3}$ result in lower MFI values [24]. Figure 1 shows the MFI tester used in the study [21-23].

Further, recycled LDPE granules without any reinforcement and with reinforcement as DPS $\mathrm{Al}_{2} \mathrm{O}_{3}$ and recycled HDPE granules without any reinforcement and with reinforcement as TPS $\mathrm{Al}_{2} \mathrm{O}_{3}$ were used for preparing the filament wires on TSE [21, 22]. The wires prepared as filament were investigated for tensile properties on a universal tensile tester (UTT). It has been reported that in case of LDPE/ HDPE, composition/proportion comes out to be the major factor contributing to peak load, break load and Young's modulus and load comes out to be the major factor contributing to peak elongation and break elongation. After analysing signal to noise (SN) ratios for multi-factor optimization, the combined effect of all the process parameters on mechanical properties was studied separately for both LDPE and HDPE [21-23].

For final confirmatory experiments the filament wires with composition/proportion were prepared for batch production using TSE as follows:

(i) primary recycled LDPE $100 \%$ by weight,

(ii) secondary recycled LDPE $50 \%$ by weight, $\mathrm{Al}_{2} \mathrm{O}_{3}$ $120 \mu \mathrm{m} 25 \%$ by weight, $\mathrm{Al}_{2} \mathrm{O}_{3}-100 \mu \mathrm{m} 25 \%$ by weight (i.e. DPS),

(iii) primary recycled HDPE $100 \%$ by weight,

Table 4. Variance analysis data SN plots.

\begin{tabular}{|c|c|c|c|c|c|c|c|c|c|c|c|c|c|}
\hline \multicolumn{7}{|c|}{ Case 1} & \multicolumn{7}{|c|}{ Case 2} \\
\hline Source & DF & Seq SS & Adj SS & Adj MS & $F$ & $P$ & Source & $\mathrm{DF}$ & Seq SS & Adj SS & $\begin{array}{l}\text { Adj } \\
\text { MS }\end{array}$ & $F$ & $P$ \\
\hline Speed & 2 & 0.0519 & 0.0519 & 0.0259 & 3.68 & 0.213 & Speed & 2 & 3.1751 & 3.1751 & 1.5876 & 7.15 & 0.123 \\
\hline Feed & 2 & 44.7473 & 44.7473 & 22.3737 & 3177.82 & 0.000 & Feed & 2 & 19.2460 & 19.2460 & 9.6230 & 43.36 & 0.023 \\
\hline Depth of cut & 2 & 0.0146 & 0.0146 & 0.0073 & 1.04 & 0.491 & Depth of cut & 2 & 0.6323 & 0.6323 & 0.3162 & 1.42 & 0.412 \\
\hline $\begin{array}{c}\text { Residual } \\
\text { error }\end{array}$ & 2 & 0.0141 & 0.0141 & 0.0070 & & & $\begin{array}{c}\text { Residual } \\
\text { error }\end{array}$ & 2 & 0.4439 & 0.4439 & 0.2219 & & \\
\hline Total & 8 & 44.8279 & & & & & Total & 8 & 23.4973 & & & & \\
\hline
\end{tabular}

Note: DF, degree of freedom; Seq SS, sequential sum of squares; Adj SS, adjusted sum of squares; Adj MS, adjusted mean of squares; $F$, Fisher's value; $P$, probability. 


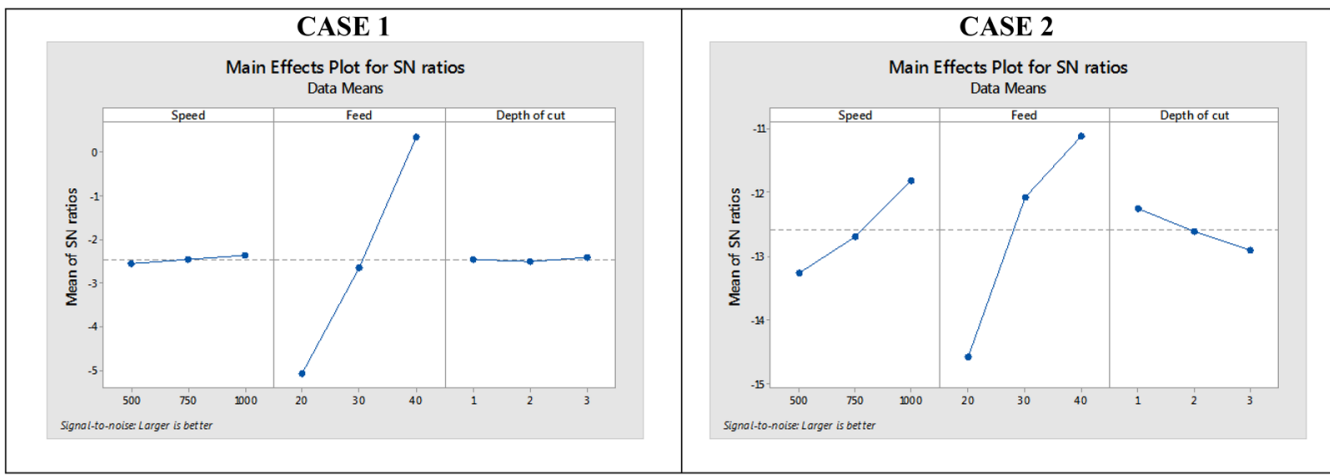

Figure 5. SN ratio plots for case 1 and case 2.

Table 6. Response table for SN plots for both cases.

\begin{tabular}{|c|c|c|c|c|c|c|c|}
\hline \multicolumn{4}{|c|}{ Case 1} & \multicolumn{4}{|c|}{ Case 2} \\
\hline Level & Speed & Feed & Depth of cut & Level & Speed & Feed & Depth of cut \\
\hline 1 & -2.5590 & -5.0885 & -2.4615 & 1 & -13.26 & -14.58 & -12.25 \\
\hline 2 & -2.4525 & -2.6594 & -2.5112 & 2 & -12.69 & -12.08 & -12.62 \\
\hline 3 & -2.3737 & 0.3626 & -2.4125 & 3 & -11.82 & -11.11 & -12.90 \\
\hline Delta & 0.1853 & 5.4511 & 0.0987 & Delta & 1.44 & 3.47 & 0.65 \\
\hline Rank & 2 & 1 & 3 & Rank & 2 & 1 & 3 \\
\hline
\end{tabular}

Table 7. Shore-D hardness and porosity values of WP.

\begin{tabular}{|c|c|c|c|c|c|c|c|c|c|}
\hline & \multirow[b]{2}{*}{ Composition } & \multirow[b]{2}{*}{$\begin{array}{l}\text { Speed } \\
(\mathrm{RPM})\end{array}$} & \multirow[b]{2}{*}{$\begin{array}{c}\text { Feed } \\
(\mathrm{mm} / \mathrm{min})\end{array}$} & \multirow[b]{2}{*}{$\begin{array}{l}\text { Depth of cut } \\
(\mathrm{mm})\end{array}$} & \multicolumn{5}{|c|}{ WP } \\
\hline & & & & & & $\begin{array}{l}\text { Hardness } \\
\text { (Zone A) }\end{array}$ & $\begin{array}{l}\text { Hardness } \\
\text { (Zone B) }\end{array}$ & $\begin{array}{c}\text { Porosity before } \\
\mathrm{m} / \mathrm{c}(\%)\end{array}$ & $\begin{array}{c}\text { Porosity after } \\
\mathrm{m} / \mathrm{c}(\%)\end{array}$ \\
\hline \multirow[t]{9}{*}{ Case 1} & 1 & 500 & 20 & 1 & \multirow[t]{9}{*}{ LDPE } & 39.5 & 43 & \multirow[t]{9}{*}{7.41} & 3.12 \\
\hline & 1 & 500 & 30 & 2 & & 40 & 46 & & 3.94 \\
\hline & 1 & 500 & 40 & 3 & & 42.5 & 41.5 & & 7.48 \\
\hline & 1 & 750 & 20 & 2 & & 41.5 & 40 & & 3.22 \\
\hline & 1 & 750 & 30 & 3 & & 40.5 & 46.5 & & 4.29 \\
\hline & 1 & 750 & 40 & 1 & & 42 & 47.5 & & 7.81 \\
\hline & 1 & 1000 & 20 & 3 & & 40 & 44.5 & & 3.47 \\
\hline & 1 & 1000 & 30 & 1 & & 39.5 & 41 & & 4.78 \\
\hline & 1 & 1000 & 40 & 2 & & 40 & 46 & & 8.42 \\
\hline \multirow[t]{9}{*}{ Case 2} & 2 & 500 & 20 & 1 & \multirow[t]{9}{*}{ HDPE } & 56.5 & 61.5 & \multirow[t]{9}{*}{15.54} & 8.47 \\
\hline & 2 & 500 & 30 & 2 & & 58.5 & 64.5 & & 12.49 \\
\hline & 2 & 500 & 40 & 3 & & 57 & 62 & & 10.22 \\
\hline & 2 & 750 & 20 & 2 & & 56 & 67 & & 9.64 \\
\hline & 2 & 750 & 30 & 3 & & 56.5 & 68 & & 11.49 \\
\hline & 2 & 750 & 40 & 1 & & 57.5 & 64 & & 12.09 \\
\hline & 2 & 1000 & 20 & 3 & & 56.5 & 65.5 & & 9.43 \\
\hline & 2 & 1000 & 30 & 1 & & 58 & 61.5 & & 10.69 \\
\hline & 2 & 1000 & 40 & 2 & & 59.5 & 63 & & 14.57 \\
\hline
\end{tabular}




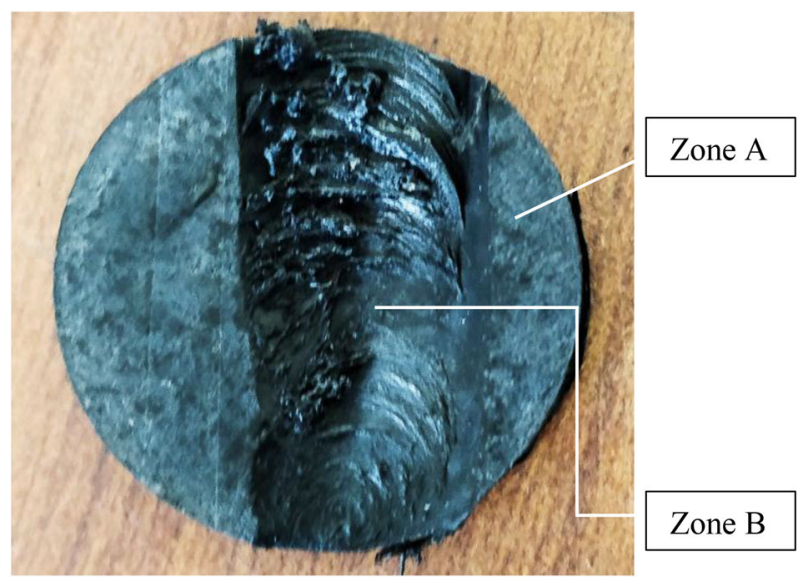

Figure 6. Machined LDPE disc

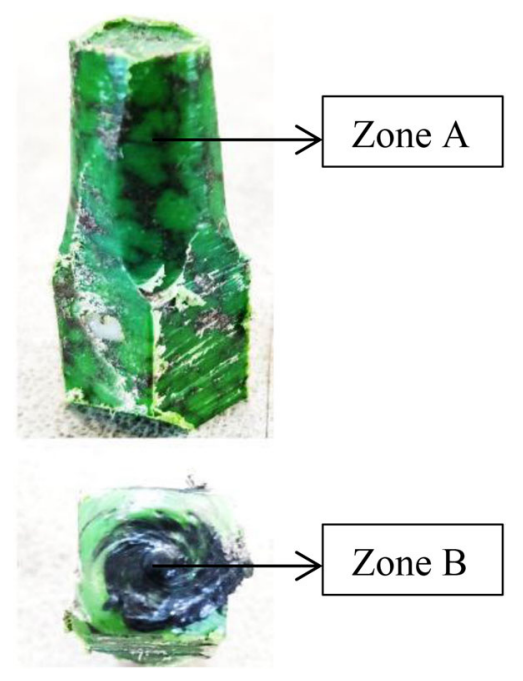

Figure 7. HDPE-TPS $\mathrm{Al}_{2} \mathrm{O}_{3}$ reinforced. RT.

(iv) secondary recycled HDPE $90 \%$ by weight, $\mathrm{Al}_{2} \mathrm{O}_{3}$ $150 \mu \mathrm{m} 3.33 \%$ by weight, $\mathrm{Al}_{2} \mathrm{O}_{3}-120 \mu \mathrm{m} 3.33 \%$ by weight, $\mathrm{Al}_{2} \mathrm{O}_{3}-100 \mu \mathrm{m} 3.33 \%$ by weight (i.e. TPS).

After preparation of the filaments, they were fed to the FDM set-up to fabricate the WP (circular discs) and RT. For analysis purpose, $18 \mathrm{WP}$ of $\Phi 40 \mathrm{~mm}$ and thickness $10 \mathrm{~mm}$ were printed (09 WP of LDPE without reinforcement and 09 WP of HDPE without reinforcement) with three repetitions to reduce the experimental error. Similarly, 18 RT of $10 \times 10 \times 35 \mathrm{~mm}^{3}$ were printed from wires prepared (as $09 \mathrm{RT}$ (secondary reinforced) of LDPEDPS $\mathrm{Al}_{2} \mathrm{O}_{3}$ and $09 \mathrm{RT}$ (secondary reinforced) of HDPETPS $\mathrm{Al}_{2} \mathrm{O}_{3}$ on FDM set-up with three repetitions. The static and input parameters considered for FDM are shown in table 1. Figure 2 shows the FDM set-up used and figure 3 shows WP and RT printed on FDM.

The 3D printed WPs (see figure 3) were machined with 3D printed RT (figure 4). Three input parameters, (i) speed (RPM) (ii) feed ( $\mathrm{mm} / \mathrm{min}$ ) and (iii) depth of cut ( $\mathrm{mm}$ ), were judicially selected with three levels of each (based upon availability in the set-up) as per Taguchi L9 orthogonal array (OA). It should be noted that for 03 parameters with 03 levels, a total of $3 \times 3 \times 3=27$ experiments (based upon full factorial approach) with 03 repetitions resulting into $27 \times 3=81$ experiments (separately for LDPE and HDPE) need to be conducted. They have been reduced to $9 \times 3=27$ sets of experiments by applying Taguchi L9 OA (for both LDPE and HDPE). Secondly the Taguchi approach is helpful to understand the factor effect on output properties statistically. Table 2 shows different levels of input parameters along with weight losses for WP and RT printed.

\section{Results and discussion}

Case 1: Primary recycled LDPE (100\% composition) WP and secondary recycled RT of HDPE-TPS $\mathrm{Al}_{2} \mathrm{O}_{3}$

In case 1, 09 samples of primary recycled LDPE (100\% by weight) WP and 09 RT of secondary recycled HDPETPS $\mathrm{Al}_{2} \mathrm{O}_{3}$ were selected. The WP was fixed on the base plate of milling machine and RT was mounted on tool post $90^{\circ}$ to WP. To compute the weight loss during the machining, initial and final weights of WP and RT were compared.

Case 2: Primary recycled HDPE (100\% composition) WP and secondary recycled RT of LDPE-DPS $\mathrm{Al}_{2} \mathrm{O}_{3}$

In case 2, 09 WPs of primary recycled HDPE $(100 \%$ by weight) and 09 RT of secondary recycled LDPE-DPS $\mathrm{Al}_{2} \mathrm{O}_{3}$ were selected.

Case 3 with primary recycled $100 \%$ LDPE (WP) and secondary recycled LDPE-DPS $\mathrm{Al}_{2} \mathrm{O}_{3}$ (RT) and Case 4 primary recycled $100 \%$ HDPE (WP) and secondary recycled HDPE-TPS $\mathrm{Al}_{2} \mathrm{O}_{3}$ (RT) were not considered as it was observed that WP and RT got joined with each other. This may be because of the fact that with similar base material, friction/friction-stir welding occurs, resulting in joining of the WP and RT in place of machining [25-28].

Based upon table 2, various $\mathrm{SN}$ ratios of weight loss of WP (as obtained by using L9 OA) separately for compositions 1 and 2 are summarized in table 3. Further, tables 4 and 5 show the variance analysis for $\mathrm{SN}$ ratios and percentage contributions of each input parameter on weight loss of WP, respectively, for both the cases.

It is noteworthy that contribution of speed and depth of cut can be neglected as $P$ value of these parameters is more than 0.05 . 


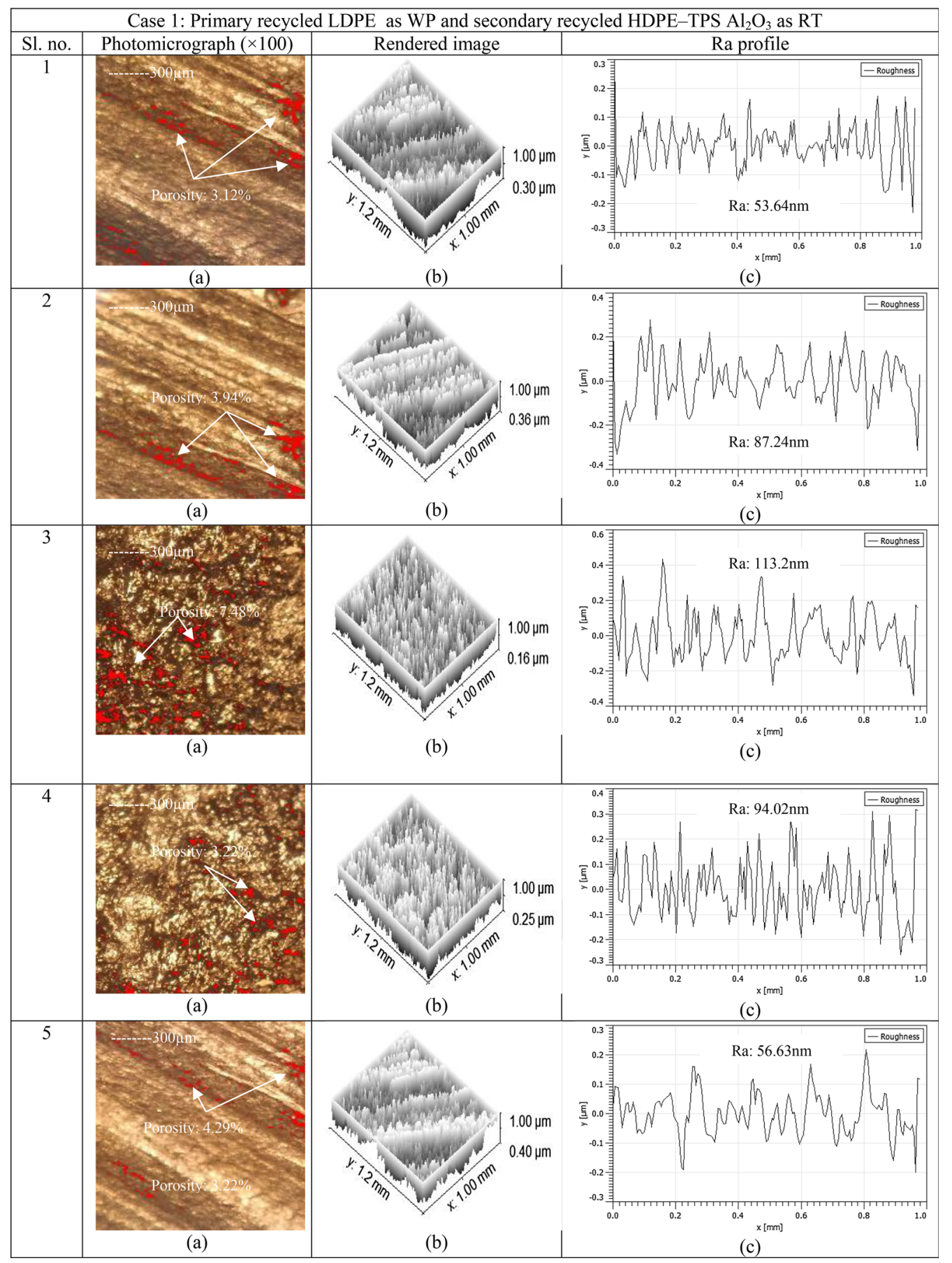

Figure 8. (a) Photomicrograph of LDPE workpieces (WP) after machining (zone B) as per table 7 case 1, (b) rendered images of photomicrographs and (c) surface roughness profile.

As observed from table 5, feed came out to be the major factor contributing to weight loss of WP in both the cases. SN plots and SN response tables for the both the cases are shown as in figure 5 and table 6 , respectively.
As observed from figure 5 and table 6 , for case 1 , speed (1000 rpm), feed $(40 \mathrm{~mm} / \mathrm{min})$ and depth of cut $(3 \mathrm{~mm})$ are the best settings and for case 2, speed (1000 rpm), feed $(40 \mathrm{~mm} / \mathrm{min})$ and depth of cut $(1 \mathrm{~mm})$ are the best settings. 


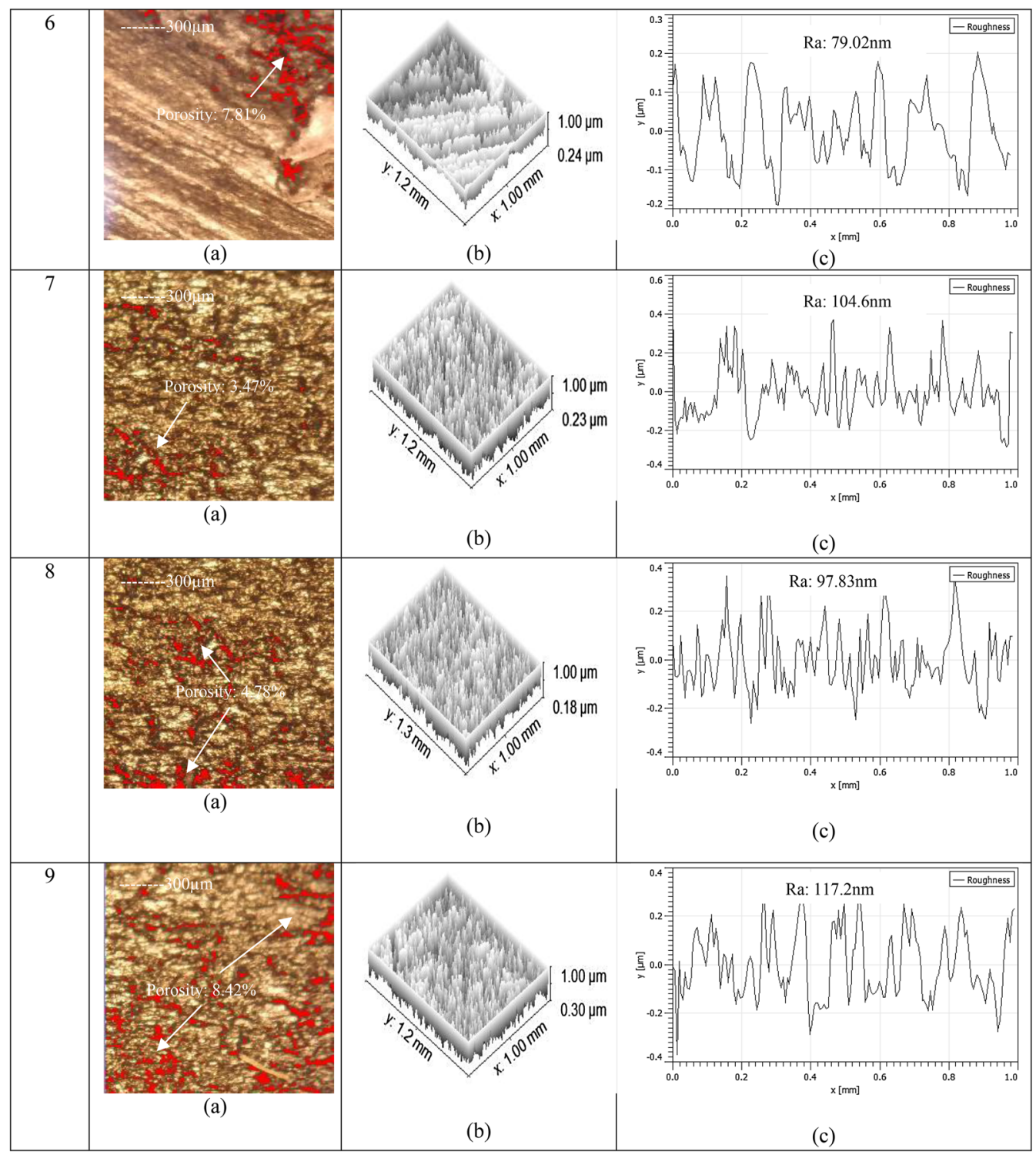

Figure 8. continued

The shore-D hardness and porosity of WPs were checked for both cases (see table 7). It is to be noted that zone A represents un-machined surface of WP and RT, whereas zone B represents machined surface of WP and RT. The porosity for machined zone was observed to be less compared with un-machined zone. This may be due to the fact that while machining with RT, material re-flow occurs over the surface of WP, resulting in controlled/reduced porosity.

For illustrative purpose, figures 6 and 7 show the machined LDPE disc and HDPE-TPS $\mathrm{Al}_{2} \mathrm{O}_{3}$-reinforced tooling used as tooling while machining. Zone B (machined portion) of WP for both the cases was examined through an optical microscope by support of software tool known as "Metallurgical image analysis software (MIAS)". Figures 8 and 9 show optical photomicrographs along with the porosity values and Ra profile for all WP prepared (with cut-off length of $0.08 \mathrm{~mm}$ ).

It can be easily interpreted from table 7 that shore-D hardness of zone A (un-machined portion) is less than that of zone B (machined portion) for the WP (which may be 


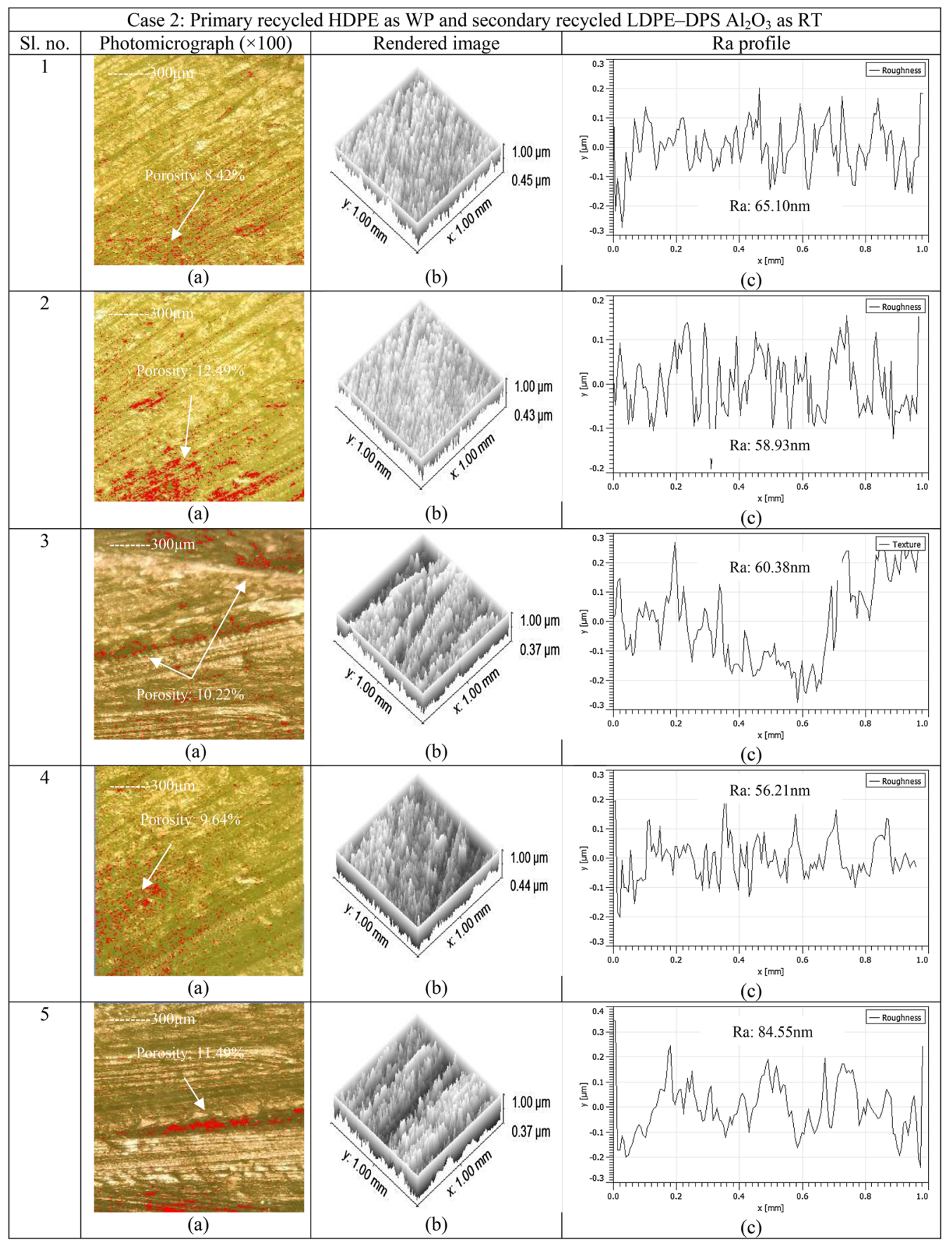

Figure 9. (a) Photomicrograph of HDPE workpieces (WP) after machining (zone B) as per table 7 case 2, (b) rendered images of photomicrographs and (c) surface roughness profile.

due to work hardening phenomenon as a result of machining) in both the cases, whereas porosity of un-machined part (zone A) is more than that of porosity of machined portion (zone B) in both the cases. The maximum hardness of machined portion of WP in case 1 came out to be 47.5 under $750 \mathrm{rpm}$, feed as $40 \mathrm{~mm} / \mathrm{min}$ and depth of cut as $1 \mathrm{~mm}$ and maximum hardness of machined portion of tooling in case 2 came out to be 68 under $750 \mathrm{rpm}$, feed as $30 \mathrm{~mm} / \mathrm{min}$ and depth of cut as $3 \mathrm{~mm}$. The minimum percentage porosity of machined portion of tooling in case 


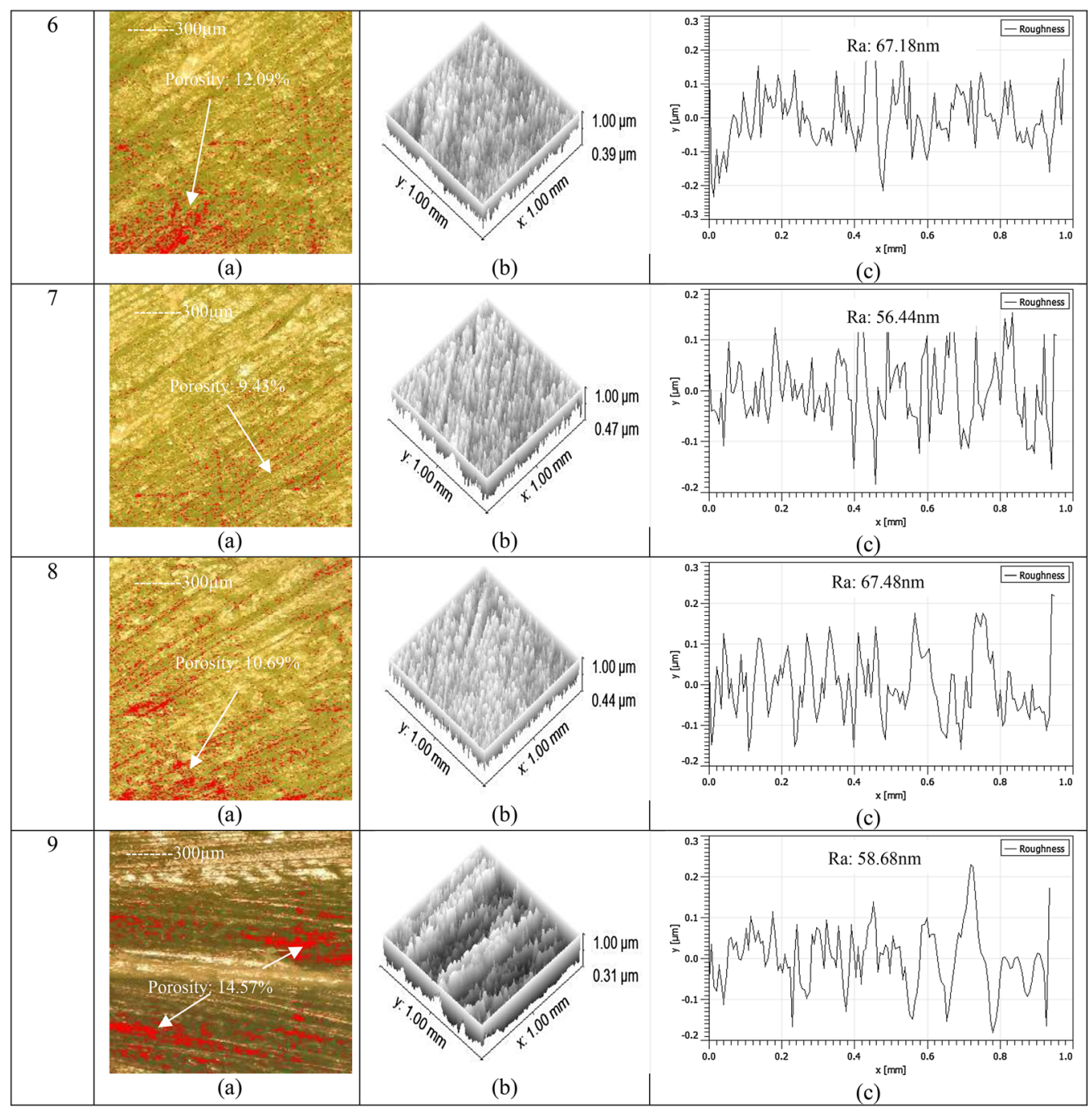

Figure 9. continued

1 came out to be $3.12 \%$ under $500 \mathrm{rpm}$, feed as $20 \mathrm{~mm} / \mathrm{min}$ and depth of cut as $1 \mathrm{~mm}$ and minimum percentage porosity of machined portion of tooling in case 2 came out to be $8.47 \%$ under $500 \mathrm{rpm}$, feed as $20 \mathrm{~mm} / \mathrm{min}$ and depth of cut as $1 \mathrm{~mm}$. Based upon figures 8 and 9 it is ascertained that LDPE is better WP material from porosity and Ra viewpoint. This may be due to the fact that better reflow of material occurred in LDPE (being a soft material in comparison with HDPE) as WP. Further, thermal analysis of machined WP with the maximum material removal (as per table 2 under case 1 and case 2) was performed for comparing zone $\mathrm{A}$ and zone $\mathrm{B}$ using DSC at controlled heating/cooling rate as $\pm 10^{\circ} \mathrm{C} / \mathrm{min}$ (figure 10). During DSC analysis, sample is heated using a controlled temperature gradient with a defined heating rate; thereby, heat flow difference is measured by comparing the sample to a reference [29-33]. Figure 10 shows that heat capacity for zone B in both cases comes out to be higher than that of zone A, giving a clear indication that machined zone is thermally more stable, which may be due to better reflow of material (in machined zone), resulting into reduced porosity. 
(a)

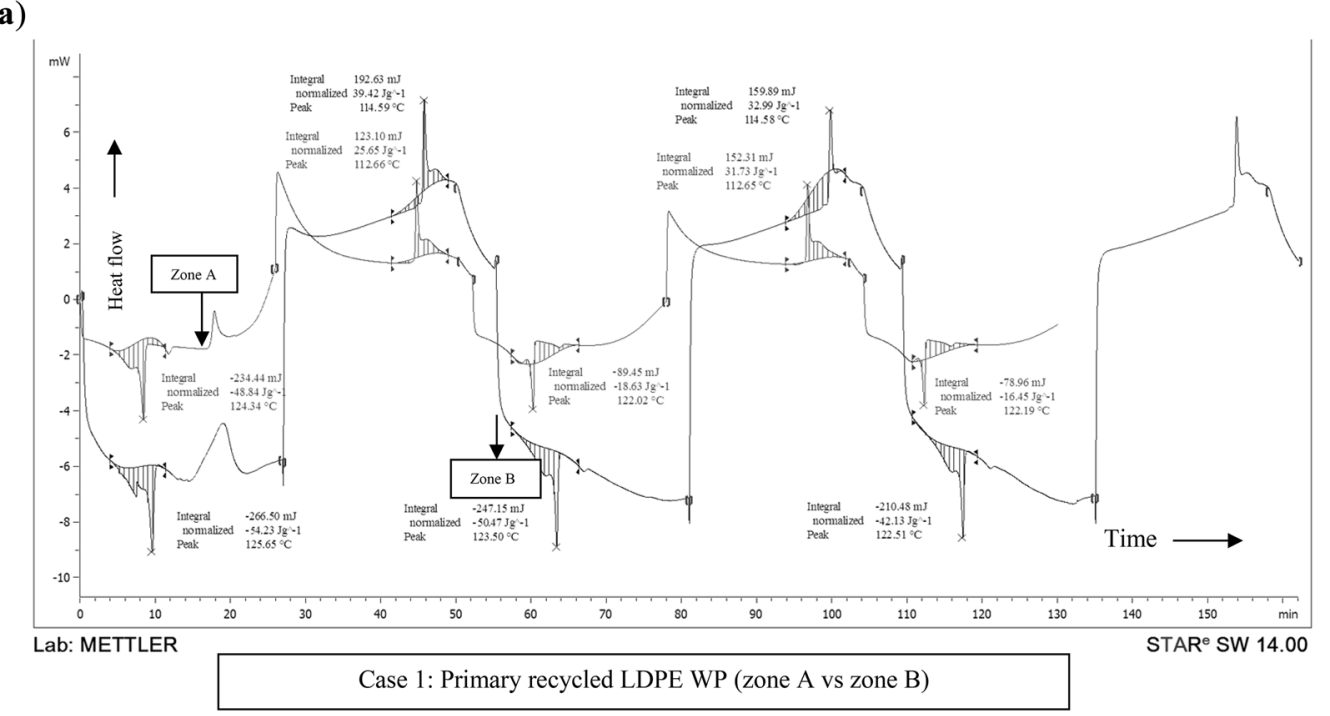

(b)

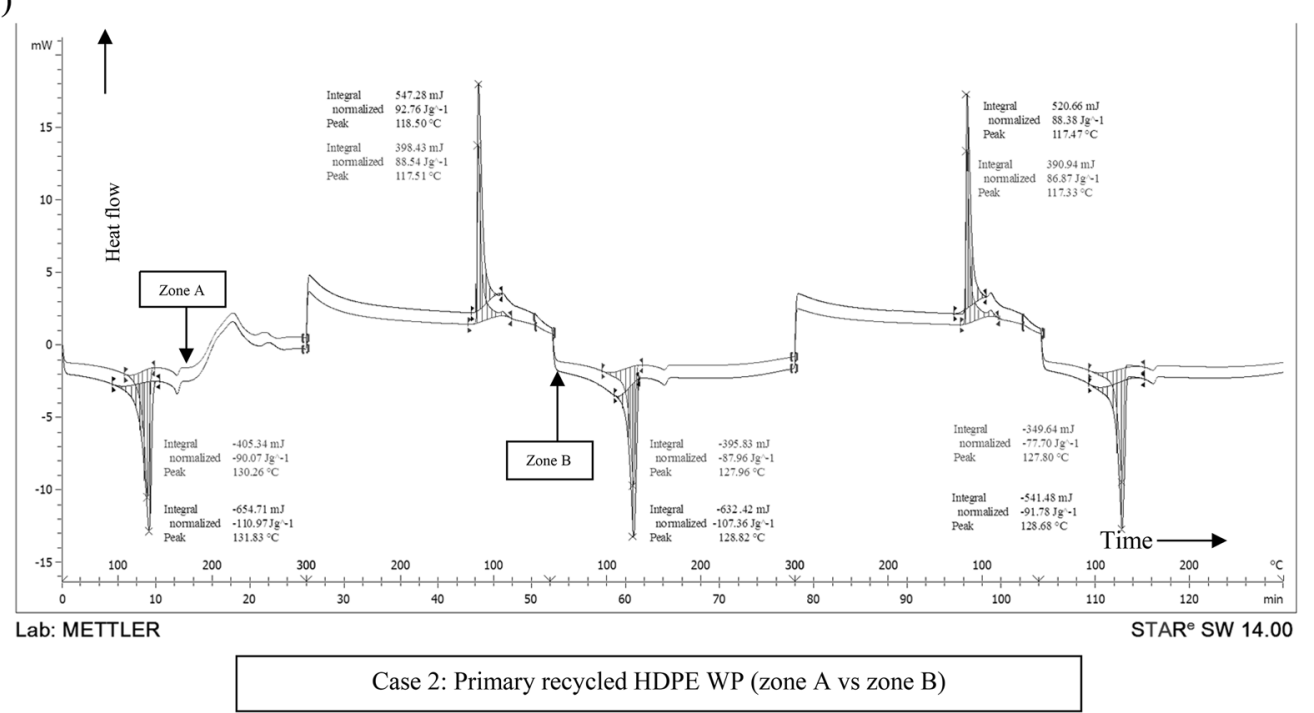

Figure 10. Comparative DSC plots of un-machined (a) and machined (b) zones for primary recycled LDPE case 1 and primary recycled HDPE case 2.

\section{Conclusions}

- The results of the study highlight that in case of primary recycled LDPE WP, $1000 \mathrm{rpm}, 40 \mathrm{~mm} / \mathrm{min}$ feed and $3 \mathrm{~mm}$ depth of cut are the best settings for better machinability of WP (machined by secondary recycled RT).

- In case of primary recycled HDPE WP: $1000 \mathrm{rpm}$, $40 \mathrm{~mm} / \mathrm{min}$ feed and $1 \mathrm{~mm}$ depth of cut are the best settings for better machinability of WP (machined by secondary recycled RT).

- The maximum hardness of machined portion of primary recycled LDPE WP (case 1) came out to be 47.5 under $750 \mathrm{rpm}$, feed as $40 \mathrm{~mm} / \mathrm{min}$ and depth of cut as $1 \mathrm{~mm}$, and maximum hardness of machined portion of primary recycled HDPE WP (case 2) came out to be 68 under $750 \mathrm{rpm}$, feed as $30 \mathrm{~mm} / \mathrm{min}$ and depth of cut as $3 \mathrm{~mm}$.

- The minimum percentage porosity of machined portion of primary recycled LDPE WP (case 1) came out to be $3.12 \%$ under $500 \mathrm{rpm}$, feed as $20 \mathrm{~mm} / \mathrm{min}$ and depth of cut as $1 \mathrm{~mm}$, and minimum percentage porosity of machined portion of primary recycled HDPE WP (case 2) came out to be $8.47 \%$ under $500 \mathrm{rpm}$, feed as $20 \mathrm{~mm} / \mathrm{min}$ and depth of cut as $1 \mathrm{~mm}$. Overall, primary recycled LDPE may be graded as a better option from machinability viewpoint.

- Since the heat capacity values for zone B for both primary recycled LDPE and HDPE WP are observed to be more than those for zone A, it may be concluded that machined portion becomes thermally more stable than un-machined. 


\section{Acknowledgements}

The authors are thankful to manufacturing research lab GNDEC, Ludhiana, for providing research facilities.

\section{References}

[1] Zheng Y, Yanful E K and Bassi A S 2005 A review of plastic waste biodegradation. Crit. Rev. Biotechnol. 25: 243-250

[2] Li X, Tabil L G and Panigrahi S 2007 Chemical treatments of natural fiber for use in natural fiber-reinforced composites: a review. J. Polym. Environ. 15: 25-33

[3] Kuo C C and Su S S 2013 A simple method of improving the surface quality of rapid prototype. Indian J. Eng. Mater. Sci. 20: 6

[4] Cruz F, Lanza S, Boudaoud H, Hoppe S and Camargo M 2012 Polymer recycling and additive manufacturing in an open source context: optimization of processes and methods. In: Proceedings of the Solid Freeform Fabrication Symposium, pp. 1591-1600

[5] Singh R, Singh S and Fraternali F 2016 Development of inhouse composite wire based feed stock filaments of fused deposition modelling for wear-resistant materials and structures. Compos. Part B Eng. 98: 244-249

[6] Hilton P D and Jacobs P F 2010 Rapid Tooling: Technologies and Industrial Applications. Marcel Dekker Inc., New York, pp. 32-38

[7] Equbal A, Sood A K and Shamim M 2015 Rapid tooling: a major shift in tooling practice. J. Manuf. Ind. Eng. 14: 1-9

[8] Trucost 2016 Plastics and sustainability: a valuation of environmental benefits, costs and opportunities for continuous improvements. https://plastics.americanchemistry.com/ Study-from-Trucost-Finds-Plastics-Reduce-EnvironmentalCosts. Retrieved 03 July 2019

[9] https://www.plasticsindustry.org. Retrieved 03 July 2019

[10] http://www.usu.edu/today/index.cfm?id=51095. Retrieved 03 July 2019

[11] http://www.letstalkplastics.com. Retrieved 03 July 2019

[12] http://www.plasticseurope.org. Retrieved 03 July 2019

[13] http://www.wrap.org.uk/content/fast-facts-plastics. Retrieved 03 July 2019

[14] https://www.azom.com/article.aspx?ArticleID=4097. Retrieved 03 July 2019

[15] Vasconcelos P, Lino F, Neto R and Vasconcelos M 2002 Design and rapid prototyping evolution. In: Proceedings of the Advanced Solutions and Development Conference, vol. 4, pp. $58-65$

[16] Afonso D and Pires L 2017 Direct rapid tooling for polymer processing using sheet metal tools. Procedia Manuf. 13: 102-108

[17] Bual G S and Kumar P 2014 Methods to improve surface finish of parts produced by fused deposition modeling. Manuf. Sci. Technol. 2: 51-55

[18] Brostow W, Datashvili T, Jiang P and Miller H 2016 Recycled HDPE reinforced with sol-gel silica modified wood sawdust. Eur. Polym. J. 76: 28-39
[19] Masood S H and Song W Q 2004 Development of new metal/polymer materials for rapid tooling using fused deposition modelling. Mater. Des. 25: 587-594

[20] Onwudili J A, Miskolczi N, Nagy J T and Lipóczi G 2016 Recovery of glass fibre and carbon fibres from reinforced thermosets by batch pyrolysis and investigation of fibre reusing as reinforcement in LDPE matrix. Compos. Part B Eng. 91: 154-161

[21] Bedi P, Singh R and Ahuja I P S 2017 Thermal characterisation of recycled HDPE reinforced with $\mathrm{Al}_{2} \mathrm{O}_{3}$. Int. J. Mater. Sci. Eng. 8(1): 107-111

[22] Singh R, Singh N, Fabbrocino F, Fraternali F and Ahuja I P S 2016 Waste management by recycling of polymers with reinforcement of metal powder. Compos. Part B Eng. 105: 23-29

[23] Bedi P, Singh R and Ahuja I P S 2018 Multifactor optimization of FDM process parameters for development of rapid tooling using $\mathrm{SiC} / \mathrm{Al}_{2} \mathrm{O}_{3}$ reinforced LDPE filament. $J$. Thermoplast. Compos. Mater. https://doi.org/10.1177/ 0892705718808572

[24] Bedi P, Singh R and Ahuja I P S 2018. Effect of $\mathrm{SiC} / \mathrm{Al}_{2} \mathrm{O}_{3}$ particle size reinforcement in recycled LDPE matrix on mechanical properties of FDM feed stock filament. Virtual Phys. Prototyp. 13(4): 246-254

[25] Kumar R, Singh R and Ahuja I P S 2019 Friction stir welding of ABS-15Al sheets by introducing compatible semi-consumable shoulder-less pin of PA6-50Al. Measurement 131: $461-472$

[26] Kumar R, Singh R, Ahuja I P S, Penna R and Feo L 2018 Weldability of thermoplastic materials for friction stir welding - a state of art review and future applications. Compos. Part B Eng. 137: 1-15

[27] Kumar R, Singh R and Ahuja I P S 2018 Investigations of mechanical, thermal and morphological properties of FDM fabricated parts for friction welding applications. Measurement 120: 11-20

[28] Kumar R, Singh R and Ahuja I P S 2019 Friction stir welding of 3D printed melt flow compatible dissimilar thermoplastic composites. Proc. Inst. Mech. Eng. Part C J. Mech. Eng. Sci. 10.1177/0954406219848465

[29] Majewsky M, Bitter H, Eiche E and Horn H 2016 Determination of microplastic polyethylene (PP) in environmental samples using thermal analysis (TGADSC). Sci. Total Environ. 568: 507-511

[30] Covas J A and Gaspar-Cunha A 2001 A computational investigation on the effect of polymer rheology on the performance of a single screw extruder. E-rheo.pt 1(1): 41-62

[31] Ferg E E and Bolo L L 2013 A correlation between the variable melt flow index and the molecular mass distribution of virgin and recycled polypropylene used in the manufacturing of battery cases. Polym. Test. J. 32(8): 1452-1459

[32] Herrera-Franco P, Valadez-Gonzalez A and Cervantes-Uc M 1997 Development and characterization of a HDPE-sandnatural fiber composite. Compos. Part B Eng. 28(3): 331-343

[33] Bedi P, Singh R and Ahuja IPS 2018 A Comprehensive Study for $3 D$ Printing of Rapid Tooling from Reinforced Waste Thermoplastics. Elsevier, Amsterdam. https://doi.org/10. 1016/B978-0-12-803581-8.11495-X 